\title{
Inhibitory Effect of Ginger and Turmeric on Rhizopus stolonifer Growth on Bread
}

\author{
Ali Muhammad ${ }^{\star}$, Ziaur Rahman, Ayub M, Durrani Y, Ali SA, Abroo Tabassum, Ashbala Shakoor, Majid Khan and Arsalan Khan \\ Department of Food Science and Technology, The University of Agriculture, Peshawar-Pakistan
}

*Corresponding author: Ali Muhammad, Department of Food Science and Technology, The University of Agriculture, Peshawar-Pakistan, Tel: 92 91 9216558; E-mail: alizypher@yahoo.com

Rec date: Apr 08, 2014; Acc date: May 05, 2014; Pub date: May 15, 2014

Copyright: (c) 2014 Muhammad A, et al. This is an open-access article distributed under the terms of the Creative Commons Attribution License, which permits unrestricted use, distribution, and reproduction in any medium, provided the original author and source are credited.

\begin{abstract}
The inhibitory effect of ginger and turmeric was studied on the Rhizopus stolonifer growth on bread. Different ratios of ginger and turmeric were incorporated to bread dough formulation. The treatments were $\mathrm{BG}_{0}$ (control), $\mathrm{BG}_{1}$ (3\% ginger), $\mathrm{BG}_{2}$ (4\% ginger), $\mathrm{BG}_{3}$ (3\% turmeric), $\mathrm{BG}_{4}$ (4\% turmeric), $\mathrm{BG}_{5}\left(1.5 \%\right.$ ginger $+1.5 \%$ turmeric) and $\mathrm{BG}_{6}$ $(2 \%$ ginger $+2 \%$ turmeric). All the samples were analyzed physicochemically (moisture, ash, $\mathrm{pH}$ and water activity), microbiologically (colony count of Rhizopus stolonifer) and organoleptically (color, texture, flavor and overall acceptability). The results showed that overall moisture decreased (from 27.46 to 26.41), water activity $a_{w}$ (from 0.89 to 0.86 ), color (from 7.4 to 5.58 ), texture (from 6.94 to 5.34 ), flavor (from 7.75 to 5.54 ) and overall acceptability (from 7.38 to 5.48), while percent ash increased (from 0.84 to 0.86 ), $\mathrm{pH}$ (from 5.95 to 6.20 ) and microbial count of Rhizopus stolonifer $\left(3.8 \times 10^{1}\right.$ to $\left.2 \times 10^{2}\right)$. The highest mean value for ash was recorded for treatment $\mathrm{BG}_{4}(0.98)$, water activity in $\mathrm{BG}_{0}$ (0.91), moisture in $\mathrm{BG}_{0}$ (29.69), $\mathrm{pH}$ in $\mathrm{BG}_{4}(6.34)$ Microbial count in $\mathrm{BG}_{0}\left(1.5 \times 10^{2} \mathrm{cfu} / \mathrm{g}\right)$, color in $B G_{3}(6.98)$, texture in $B G_{0}(7.04)$, flavor in $B G_{0}(6.90)$ and overall acceptability in $B G_{0}$ and $B G_{3}(6.96)$. The overall results showed that $\mathrm{BG}_{3}$ gave the best inhibitory results against Rhizopus stolonifer as well as in physicochemical and sensory evaluation, while BG6 also presented better inhibitory results in microbial analysis but it was not satisfactory in terms of sensory characteristics.
\end{abstract}

Keywords: Ginger; Turmeric; Rhizopos stolonifer, Bread

\section{Introduction}

In terms of both production and utilization, bread is given a special importance in baking industry as compared to all other bakery items. Due to the supportive nature of bread ingredients, bread serves as a media for production, reproduction and multiplication of microorganisms. The common microorganisms responsible for the spoilage of bread are Aspergillus niger, Aspergillus flavus and Rhizopus stolonifer [1]. Among these three, the most destructive and common species in bread is Rhizopus stolonifer, generally known as "black bread mold". Most often, the growth of mold initiates with the moisture abundant part of a bread slice, particularly the crease [2].

Bread is basic portion of our routine intake; therefore, studies should be carried out to discover new techniques for extending its storage life. The basic means to increase the shelf life of bread includes sterile environment of baking area, disinfecting mixing premises and guaranteeing sterilized conditions. Numerous chemical antimicrobial agents have been implemented for the improving the shelf life of bread but they are measured liable for toxic and carcinogenic effect in foods. Therefore, consumers hesitate to use foods added with chemical preservatives or improvers and the demand for alternative natural preservatives has increased significantly [3]. Recently, many researchers have attempted the utilization of oils and extracts of many herbs and spices for improving shelf life of foods and to use it as alternative for food preservatives [4-6].

In this era, consumers tend to use safer foods in order to save themselves from being victims of numerous non-communicable illnesses. Therefore, industrialists and food researchers are trying to improvise the quality, standard, safety and variety of food products including bread [7]. For this purpose, they are including natural spices and herbs as optional ingredients in their product formulations. These ingredients are also vital portion of daily diet. For centuries, spices and herbs have been part of food items for the improvement of color, aroma and flavor of food items and as functioning agents for their anti-oxidative, preservative and antimicrobial effect [7].

Turmeric is a member of the ginger family, Zingaberaceae. It is a natural spice, obtained from the root Curcuma longa [8]. It is bright yellow in color and has been used as a coloring agent in food in USA. It has been used for thousand years as a spice, a food preservative and also for medicinal properties in India (Eigner and Scholz, 1999) [9].

Nowadays, researchers are showing substantial interest in the active compounds of turmeric known as curcuminoids. The main curcuminoid is curcumin (diferuloyl methane), which constitutes about $90 \%$ of the turmeric curcuminoid contents, followed by demethoxycurcumin and bisdemethoxycurcmin [10]. Turmeric oil has high antibacterial activity and it was confirmed by testing it against Bacillus coagulans, Bacillus cereus, Bacillus subtilis, Escherichia coli, Staphylococcus aureus and Pseudomonas aeruginosa. The antifungal activity of turmeric oil was examined against Aspergillus parasiticus, Aspergillus flavus, Penicillium digitatum and Fusarium moniliforme. After combination with fluconazole or amphotericin B, curcumin showed a greater fungicidal effect in the treatment of systemic fungal infections including candidemia and candidiasis. Even though turmeric has several health improving benefits, still plenty research is needed for the support of powder turmeric being part of our food formulations. Nevertheless, its antimycotic and antioxidative activity has already been reported in butter cakes [11]. 
Reports revealed that curcuminoids of turmeric have high stability and the level of any cucuminoid is not affected by heating. This quality makes turmeric extremely acclaimed source of functional food constituents like Curcumin [12]. It has been concluded from earlier studies that incorporation of turmeric powder highly improved the antioxidant action of bread. The enhanced antioxidant action of turmeric-bread may probably be due to the integration of phenolic substances like curcumin, which own high antioxidant activity [13].

Ginger (Zingiber officinale), belongs to subtropical and tropical family Zingiberaceae, which originated from South Eastern parts of Asia and spread to most of the world regions. Ginger comprises naturally active contents which include the key spicy codes, the shogaols and gingerols [14]. Gingerols, which are phenolic in nature, are responsible for the pungency of fresh ginger. Gingerol is present most abundantly and some other gingerols of shorter chains are also there in smaller ratio. The sharp smell of ginger is due to shogaols, which is the dehydrated form of gingerol. Gingerols are converted to corresponding shogaols by heating [15]. Both gingerols and shogaols have high antioxidant activity $[16,17]$, specifically, gingerol is known for its strong antioxidant activity both in vivo and in vitro, as well as for its strong antiapoptotic and antiinflammatory actions [18].

Ginger is available as fresh, dried, powdered, oleoresin, candy (crystallized ginger), preserved in brine or syrup, and in oil form. Ginger is an essential component of food formulations and processing all over the globe due to its biting taste, refreshing pleasant aroma, and carminative characteristics. In western world, it is used broadly for the purpose of cooking in biscuits, ginger breads, cakes, soups, puddings and pickles. In eastern countries, fresh ginger slices, chops, small pieces and ground ginger are extensively used in non-vegetarian and vegetarian foods. Its usage in soft drink preparation, pickling, confectionery and curry powder development is also known [19].

\section{Materials and Methods}

The research work was conducted in the laboratory of the Department of Food Science and Technology, The University of Agriculture, Peshawar, Pakistan.

\section{Application of turmeric and ginger to dough}

Ginger powder and turmeric powder substitutions were 3\% and $4 \%$ in wheat flour and were also used in combination at the same levels as described by Lim et al. [20]. 0, 30 and 40 grams of turmeric powder were incorporated in 1000, 970 and 960 grams wheat flour, respectively. Same substitutions were used for ginger powder. In case of combination of both turmeric and ginger, half amount of both were applied, respectively. Amounts of all other ingredients were similar in these different formulations.

\section{Preparation of bread}

The bread was prepared from straight grade flour, according to AACC [21] method 10-09 (12). Wheat flour (1000 g), sugar (60 g), salt $(20 \mathrm{~g})$, oil (40 g), yeast (12 g), bread improver ( $7 \mathrm{~g})$ and water (adjusted accordingly) were mixed together with the help of mixer. This mixed dough was then rested at $30^{\circ} \mathrm{C}$ for 2 hours. The developed dough was distributed into fragments each having the same mass, molded by hands and kept in baking pans that were already lubricated with oil. These dough fragments were then transferred into a proofing chamber at $70 \%$ humidity and $30^{\circ} \mathrm{C}$ for 50 minutes. The molded loaves were then baked in an oven at $250^{\circ} \mathrm{C}$ for 20 minutes. Before depanning, these were rested for some time to become cold. After cooling, the baked breads were packaged in polyethylene bags.

\section{Treatments}

$$
\begin{aligned}
& \text { - } \mathrm{BG}_{0}=\text { Control (without turmeric and ginger) } \\
& \text { - } \mathrm{BG}_{1}=3 \% \text { ginger } \\
& \text { - } \mathrm{BG}_{2}=4 \% \text { ginger } \\
& \text { - } \mathrm{BG}_{3}=3 \% \text { turmeric } \\
& \text { - } \mathrm{BG}_{4}=4 \% \text { turmeric } \\
& \text { - } \mathrm{BG}_{5}=1.5 \% \text { ginger }+1.5 \% \text { turmeric } \\
& \mathrm{BG}_{6}=2 \% \text { ginger }+2 \% \text { turmeric }
\end{aligned}
$$

\section{Microbiological analysis}

Inoculation of Rhizopus stolonifer to bread: Common Bread Mold, Rhizopus stolonifer, was grown on PDA medium and the fungal species were morphologically and microscopically identified in the Department of Plant Pathology, The University of Agriculture, Peshawar-Pakistan. After identification, the mold was inoculated in the center of all the bread loaves with the help of inoculation needle to provide a rounded inoculum of about $2 \mathrm{~mm}$ diameter.

Colony counting: Colony count of Rhizopus stolonifer in bread was calculated at $0,24,48,72$ and $96 \mathrm{~h}$ of storage on yeast and mold agar media by plate count technique as described by Beneke (1962) [22].

$\mathrm{Cfu} / \mathrm{g}=$ No. of colonies $\times$ Dilution factor $\times$ volume factor.

Physicochemical Analysis: The samples were analyzed for moisture, ash, $\mathrm{pH}$, total dissolved solids and water activity by the standard methods of AOAC [23].

Water activity (aw): Water activity (aw) was calculated with the help of Novaseina R.T.D 502 apparatus (Novaseina, Pfapfikkion, Switzerland).

Sensory evaluation: The bread samples were assessed organoleptically for color, texture, flavor and overall acceptability with the method of Larmond [24].

Statistical analysis: The results of various treatments were analyzed statistically by using simple CRD and the means were compared by using LSD (Least Significant Difference) test. For all the analyses, the alpha error was set at $0.05 \%$ [25].

\section{Results and Discussion}

Products prepared from flour are considered as major diet for all human beings. Several studies were carried out on the preservation and shelf life extension of bakery products, mainly bread. Molds and yeasts usually deteriorate these products. Among them, Rhizopus stolonifer stands at the top in the list of bread spoilage. In order to inhibit this mold growth, many methods can be employed including the addition of food grade spices that also contain other benefits.

All the bread samples were prepared with total care and were brought to the laboratory of Food Science and Technology, The University of Agriculture, Peshawar, Pakistan for different physicochemical analysis. All the samples were stored at room temperature and were analyzed for $\%$ moisture, ash, $\mathrm{pH}$, water activity and microbial count that included Rhizopus stolonifer colony count on daily basis. Samples were also evaluated organoleptically at 24 hours interval. 


\section{Microbiological analysis}

At the start of the experiment, the microbiological values of the samples for Rhizopus stolonifer count were recorded as, 0.00 which were progressively increased to $2.9 \times 10^{2}, 2.3 \times 10^{2}, 2.2 \times 10^{2}, 1.8 \times 10^{2}, 2.6$ $\mathrm{x} 10^{2}, 1.9 \times 10^{2}$ and $1.9 \times 10^{2} \mathrm{cfu} / \mathrm{g}$ respectively during 96 hours of storage. The mean microbial values considerably $(\mathrm{P}<0.05)$ increased from 0.00 to $2.2 \times 10^{2}$ through storage. For treatments, highest mean values was noted in $\mathrm{BG}_{0}\left(1.9 \times 10^{2}\right)$, followed by $\mathrm{BG}_{4}\left(1.5 \times 10^{2}\right)$ and lowest mean value was noted in $\mathrm{BG}_{3}\left(8.6 \times 10^{2}\right)$ followed by $\mathrm{BG}_{6}(9.0$ $\left.\mathrm{x} 10^{2}\right)$. Highest percent increase was noted in $\mathrm{BG}_{2}(600 \%)$, followed by $\mathrm{BG}_{4}(375 \%)$ and $\mathrm{BG}_{5}(320 \%)$ while lowest percent reduce was noted in $\mathrm{BG}_{6}(111 \%)$, followed by $\mathrm{BG}_{3}(150 \%)$.

\begin{tabular}{|c|c|c|c|c|c|c|c|}
\hline \multicolumn{8}{|c|}{ Storage intervals (hours) } \\
\hline $\begin{array}{l}\text { Treatme } \\
\text { nts }\end{array}$ & $\begin{array}{l}0 \\
\text { Hours }\end{array}$ & $\begin{array}{l}24 \\
\text { Hours }\end{array}$ & $\begin{array}{l}48 \\
\text { Hours }\end{array}$ & $\begin{array}{l}72 \\
\text { Hours }\end{array}$ & $\begin{array}{l}96 \\
\text { Hours }\end{array}$ & $\begin{array}{l}\% \\
\text { Increase }\end{array}$ & Means \\
\hline $\mathrm{BG}_{0}$ & 0 & $7 \times 10^{2}$ & $1.6 \times 10^{2}$ & $2.1 \times 10^{2}$ & $2.7 \times 10^{2}$ & 285.71 & $\begin{array}{l}1.5 \times 10^{2} \\
a\end{array}$ \\
\hline $\mathrm{BG}_{1}$ & 0 & $6 \times 10^{2}$ & $1.1 \times 10^{2}$ & $1.8 \times 10^{2}$ & $2.2 \times 10^{2}$ & 266.67 & $\begin{array}{l}1.1 \times 10^{2} \\
b\end{array}$ \\
\hline $\mathrm{BG}_{2}$ & 0 & $3 \times 10^{2}$ & $1.1 \times 10^{2}$ & $1.7 \times 10^{2}$ & $2.1 \times 10^{2}$ & 600 & $\begin{array}{l}1.0 \times 10^{2} \\
b c\end{array}$ \\
\hline $\mathrm{BG}_{3}$ & 0 & 0 & $6 \times 10^{2}$ & $9 \times 10^{2}$ & $1.5 \times 10^{2}$ & 150 & $6 \times 10^{1} d$ \\
\hline $\mathrm{BG}_{4}$ & 0 & $4 \times 10^{1}$ & $1.2 \times 10^{2}$ & $1.6 \times 10^{2}$ & $1.9 \times 10^{2}$ & 375 & $\begin{array}{l}1.0 \times 10^{2} \\
b c\end{array}$ \\
\hline $\mathrm{BG}_{5}$ & 0 & $5 \times 10^{1}$ & $1.3 \times 10^{2}$ & $1.5 \times 10^{2}$ & $2.1 \times 10^{2}$ & 320 & $\begin{array}{l}1.0 \times 10^{2} \\
\text { bc }\end{array}$ \\
\hline $\mathrm{BG}_{6}$ & 0 & 0 & $9 \times 10^{1}$ & $1.6 \times 10^{2}$ & $1.9 \times 10^{2}$ & 111.11 & $\begin{array}{l}8.8 \times 10^{2} \\
c\end{array}$ \\
\hline Means & $0.00 \mathrm{e}$ & $\begin{array}{l}3.8 \times 10^{2} \\
d\end{array}$ & $\begin{array}{l}1.1 \times 10^{2} \\
c\end{array}$ & $\begin{array}{l}1.6 \times 10^{2} \\
b\end{array}$ & $2 \times 10^{2} a$ & & \\
\hline
\end{tabular}

Table 1: Effect of treatments and storage intervals Rhizopus stolonifer growth on bread samples (cfu/g).

\begin{tabular}{|l|l|l|l|l|l|l|l|}
\hline \multicolumn{6}{|l}{ Storage intervals (hours) } \\
\hline $\begin{array}{l}\text { Treatmen } \\
\text { ts }\end{array}$ & $\begin{array}{l}\mathbf{0} \\
\text { Hours }\end{array}$ & $\begin{array}{l}\mathbf{2 4} \\
\text { Hours }\end{array}$ & $\begin{array}{l}\mathbf{4 8} \\
\text { Hours }\end{array}$ & $\begin{array}{l}\mathbf{7 2} \\
\text { Hours }\end{array}$ & $\begin{array}{l}\mathbf{9 6} \\
\text { Hours }\end{array}$ & $\begin{array}{l}\text { \% } \\
\text { Increase }\end{array}$ & Means \\
\hline $\mathrm{BG}_{0}$ & 31.1 & 29.73 & 29.45 & 29.11 & 29.06 & 6.56 & $\begin{array}{l}29.690 \\
\mathrm{a}\end{array}$ \\
\hline $\mathrm{BG}_{1}$ & 26.54 & 26.36 & 26.18 & 25.91 & 25.79 & 2.83 & $26.15 \mathrm{~d}$ \\
\hline $\mathrm{BG}_{2}$ & 24.2 & 24.07 & 23.92 & 23.83 & 23.77 & 1.78 & $23.95 \mathrm{f}$ \\
\hline $\mathrm{BG}_{3}$ & 27.87 & 27.68 & 27.53 & 27.41 & 27.29 & 2.08 & $27.55 \mathrm{c}$ \\
\hline $\mathrm{BG}_{4}$ & 28.96 & 28.62 & 28.01 & 27.78 & 27.45 & 5.21 & $28.16 \mathrm{~b}$ \\
\hline $\mathrm{BG}_{5}$ & 27.82 & 27.45 & 27.23 & 27.04 & 26.89 & 3.34 & $27.28 \mathrm{c}$ \\
\hline $\mathrm{BG}_{6}$ & 25.76 & 25.37 & 25.18 & 24.93 & 24.64 & 4.35 & $25.17 \mathrm{e}$ \\
\hline $\mathrm{Means}$ & $\begin{array}{l}27.46 \\
\mathrm{a}\end{array}$ & $27.04 \mathrm{~b}$ & $\begin{array}{l}26.78 \mathrm{~b} \\
\mathrm{c}\end{array}$ & $\begin{array}{l}26.57 \mathrm{c} \\
\mathrm{d}\end{array}$ & $26.41 \mathrm{~d}$ & & \\
\hline
\end{tabular}

Table 2: Effect of treatments and storage intervals on moisture percentage of the bread samples.
The statistical analysis showed that the treatments and storage intervals had a considerable $(\mathrm{P}<0.05)$ effect on Rhizopus stolonifer count of bread sample through storage at ambient temperature. The means were divided by applying LSD test at $5 \%$ probability level and standard deviation was applied to the data (Table 1).

The results of microbiological study are in close resemblance to that of the mold growth on bread, reported by Rehman et al., [26] at same storage intervals. Below water activity value of 0.950 , yeasts and molds are the cause of most biological alterations of foods [27].

\section{Moisture}

At the start of the experiment, the moisture content of the samples were $31.1,26.54,24.2,27.87,28.96,27.82$ and $25.76 \%$ which were gradually decreased to $29.06,25.79,23.77,27.29,27.45,26.89$ and $24.64 \%$ respectively during 96 hours of storage. The mean moisture values considerably $(\mathrm{P}<0.05)$ decreased from 27.46 to 26.41 through storage. For treatments, highest mean values was noted in $\mathrm{BG}_{0}$ (29.69\%), followed by $\mathrm{BG}_{4}(28.16 \%)$ and lowest mean value was noted in $\mathrm{BG}_{2}(23.95 \%)$, followed by $\mathrm{BG}_{6}(25.17 \%)$. Highest percent decrease was noted in $\mathrm{BG}_{0}(6.56 \%)$ followed by $\mathrm{BG}_{4}$ (5.21\%) while lowest percent reduce was noted in $\mathrm{BG}_{2}(1.78 \%)$, followed by $\mathrm{BG}_{3}(2.08 \%)$ (Table 1).

The statistical analysis showed that the treatments and storage intervals had a considerable $(\mathrm{P}<0.05)$ effect on moisture of bread sample through storage at ambient temperature. The means were divided by applying LSD test at $5 \%$ probability level and standard deviation was applied to the data (Table 2).

In a similar study, decrease in the moisture of freshly baked bread was observed by him and Hoseney. He reported that bread crumb moisture decreased sharply with time. The crumb of freshly baked bread contained about $47 \%$ moisture. However, during 2 hours of cooling the moisture dropped to $41 \%$. Fik et al. [28] in his study observed that the moisture content of calcium enriched bread decreased by $9 \%$ in 3 days of initial storage.

\section{Ash}

At the start of the experiment, the ash content of the samples were $0.79,0.78,0.830 .90,0.96,0.80$ and $0.82 \%$ which were gradually increased to $0.82,0.81,0.86,0.92,0.99,0.81$ and $0.84 \%$ respectively during 96 hours of storage. The mean ash content increased from 0.84 to $0.86 \%$ through storage. For treatments, highest mean value was noted in $\mathrm{BG}_{3}(0.98)$ followed by $\mathrm{BG}_{6}(0.90 \%)$ and lowest mean value was noted in $\mathrm{BG} 0(0.79 \%)$ followed by $\mathrm{BG}_{2}(0.80 \%)$. Highest percent increase was noted in $\mathrm{BG}_{0}(3.70 \%)$ followed by $\mathrm{BG}_{2}(3.66 \%)$ while lowest percent reduce was noted in $\mathrm{BG}_{1}(1.23 \%)$ followed by $\mathrm{BG}_{6}$ (2.17\%) (Table 3).

The statistical analysis showed that the treatments and storage intervals had a considerable $(\mathrm{P}<0.05)$ effect on ash content of the bread samples during storage at ambient temperature. The means were separated by applying LSD test at $5 \%$ probability level and standard deviation was applied to the data. The ash content in control bread was $0.79 \%$ but with the addition of turmeric, this quantity was increased. This anomalous increase of ash content might be due to the fact that ash content in turmeric powder is about four times higher than that of wheat flour, as reported previously by Kang [29]. In another study, Bojnanska et al. [30] observed $0.80 \%$ ash in control bread and this aggregate increased with the addition of pulses into the bread that 
contain large amount of ash. This finding is closely related to observations of the present study.

\begin{tabular}{|l|l|l|l|l|l|l|l|}
\hline \multicolumn{6}{|l}{ Storage intervals (hours) } \\
\hline $\begin{array}{l}\text { Treatmen } \\
\text { ts }\end{array}$ & $\begin{array}{l}\mathbf{0} \\
\text { Hours }\end{array}$ & $\begin{array}{l}\mathbf{2 4} \\
\text { Hours }\end{array}$ & $\begin{array}{l}\mathbf{4 8} \\
\text { Hours }\end{array}$ & $\begin{array}{l}\mathbf{7 2} \\
\text { Hours }\end{array}$ & $\begin{array}{l}\mathbf{9 6} \\
\text { Hours }\end{array}$ & $\begin{array}{l}\% \\
\text { Increase }\end{array}$ & $\begin{array}{l}\text { Mean } \\
\mathbf{s}\end{array}$ \\
\hline $\mathrm{BG}_{0}$ & 0.79 & 0.8 & 0.8 & 0.81 & 0.82 & 3.66 & $0.80 \mathrm{~d}$ \\
\hline $\mathrm{BG}_{1}$ & 0.78 & 0.79 & 0.79 & 0.8 & 0.81 & 3.7 & $0.79 \mathrm{e}$ \\
\hline $\mathrm{BG}_{2}$ & 0.83 & 0.84 & 0.83 & 0.85 & 0.86 & 3.49 & $0.84 \mathrm{c}$ \\
\hline $\mathrm{BG}_{3}$ & 0.9 & 0.91 & 0.91 & 0.9 & 0.92 & 2.17 & $0.90 \mathrm{~b}$ \\
\hline $\mathrm{BG}_{4}$ & 0.96 & 0.98 & 0.98 & 0.99 & 0.99 & 3.03 & $0.98 \mathrm{a}$ \\
\hline $\mathrm{BG}_{5}$ & 0.8 & 0.81 & 0.82 & 0.82 & 0.81 & 1.23 & $0.81 \mathrm{~d}$ \\
\hline $\mathrm{BG}_{6}$ & 0.82 & 0.84 & 0.84 & 0.85 & 0.84 & 2.38 & $0.83 \mathrm{c}$ \\
\hline $\mathrm{Means}$ & $0.84 \mathrm{c}$ & $0.85 \mathrm{~b}$ & $0.85 \mathrm{~b}$ & $0.86 \mathrm{a}$ & $0.86 \mathrm{a}$ & & \\
\hline
\end{tabular}

Table 3: Effect of treatments and storage intervals on ash percentage of the bread samples.

\begin{tabular}{|l|l|l|l|l|l|l|l|}
\hline \multicolumn{6}{|l}{ Storage intervals (hours) } \\
\hline $\begin{array}{l}\text { Treatmen } \\
\text { ts }\end{array}$ & $\begin{array}{l}\mathbf{0} \\
\text { Hours }\end{array}$ & $\begin{array}{l}\mathbf{2 4} \\
\text { Hours }\end{array}$ & $\begin{array}{l}\mathbf{4 8} \\
\text { Hours }\end{array}$ & $\begin{array}{l}\mathbf{7 2} \\
\text { Hours }\end{array}$ & $\begin{array}{l}\mathbf{9 6} \\
\text { Hours }\end{array}$ & $\begin{array}{l}\text { \% } \\
\text { Increase }\end{array}$ & $\begin{array}{l}\text { Mean } \\
\text { s }\end{array}$ \\
\hline $\mathrm{BG}_{0}$ & 5.9 & 5.9 & 5.9 & 6 & 6 & 1.69 & $5.94 \mathrm{~d}$ \\
\hline $\mathrm{BG}_{1}$ & 6 & 6 & 6.1 & 6.1 & 6.1 & 1.66 & $6.06 \mathrm{c}$ \\
\hline $\mathrm{BG}_{2}$ & 5.8 & 5.9 & 5.9 & 6 & 6.1 & 5.17 & $5.94 \mathrm{~d}$ \\
\hline $\mathrm{BG}_{3}$ & 6.1 & 6.1 & 6.2 & 6.2 & 6.2 & 1.64 & $\begin{array}{l}6.16 \mathrm{~b} \\
\mathrm{c}\end{array}$ \\
\hline $\mathrm{BG}_{4}$ & 6.3 & 6.3 & 6.3 & 6.4 & 6.4 & 1.59 & $6.34 \mathrm{a}$ \\
\hline $\mathrm{BG}_{5}$ & 6 & 6.1 & 6.2 & 6.3 & 6.4 & 5 & $6.20 \mathrm{~b}$ \\
\hline $\mathrm{BG}_{6}$ & 5.6 & 5.7 & 5.9 & 6 & 6.2 & 10.71 & $5.88 \mathrm{~d}$ \\
\hline $\mathrm{Means}$ & $5.95 \mathrm{~d}$ & $6.00 \mathrm{~cd}$ & $6.07 \mathrm{bc}$ & $6.14 \mathrm{ab}$ & $6.20 \mathrm{a}$ & & \\
\hline
\end{tabular}

Table 4: Effect of treatments and storage intervals on $\mathrm{pH}$ of the bread samples.

\section{pH}

At the start of the experiment, the $\mathrm{pH}$ values of the samples were $5.6,5.9,5.8,6.3,6.1,6$, and 6 , which gradually increased to $6.2,6,6.1$, $6.4,6.2,6.1$ and 6.4 respectively during 96 hours of storage. The mean $\mathrm{pH}$ values considerably $(\mathrm{P}<0.05)$ increased from 5.95 to 6.20 through storage. For treatments, highest mean values was noted in $\mathrm{BG}_{3}$ (6.34), followed by $\mathrm{BG}_{6}(6.20)$ and lowest mean value was noted in $\mathrm{BG}_{0}$ (5.88), followed by $\mathrm{BG}_{1}$ and $\mathrm{BG}_{2}$ (5.94). Highest percent increase was noted in $\mathrm{BG}_{0}(10.71 \%)$, followed by $\mathrm{BG}_{2}(5.17 \%)$ while lowest percent reduce was noted in $\mathrm{BG}_{3}(1.59 \%)$, followed by $\mathrm{BG}_{4}(1.64 \%)$ (Table 4$)$.

The statistical analysis showed that the treatments and storage intervals had a considerable $(\mathrm{P}<0.05)$ effect on $\mathrm{pH}$ of the bread samples through storage at ambient temperature. The means were divided by applying LSD test at $5 \%$ probability level and standard deviation was applied to the data (Table 4).

In a similar study, Shin et al. [31] found $\mathrm{pH}$ values of breads from 6.28 to 6.08 . They further documented that change in $\mathrm{pH}$ of breads was due to the fermentation process. Rhizopus stolonifer shows the highest amylase activity $(3.9 \mathrm{mg} / \mathrm{l})$ at $\mathrm{pH} 6[1]$.

\section{Water activity}

At the start of the study, the water activity $\left(\mathrm{a}_{\mathrm{W}}\right)$ of the samples were $0.92,0.90,0.90,0.89,0.87,0.89$ and 0.88 , which were gradually decreased to $0.91,0.88,0.87,0.86,0.84,0.87$ and 0.85 respectively during 96 hours of storage. The mean water activity values considerably $(\mathrm{P}<0.05)$ decreased from 0.89 to 0.86 through storage. For treatments, highest mean values was noted in $\mathrm{BG}_{0}(0.91)$, followed by $\mathrm{BG}_{1}(0.89)$ and lowest mean value was noted in $\mathrm{BG}_{4}(0.85)$, followed by $\mathrm{BG}_{6}(0.86)$. Highest percent decrease was noted in $\mathrm{BG}_{4}$ (3.45\%), followed by $\mathrm{BG}_{3}$ and $\mathrm{BG}_{2}(3.37 \%)$ while lowest percent reduce was noted in $\mathrm{BG}_{0}(1.09 \%)$, followed by $\mathrm{BG}_{1}(2.22 \%)$ (Table 5).

The statistical analysis showed that the treatments and storage intervals had a considerable $(\mathrm{P}<0.05)$ effect on water activity of the bread samples through storage at ambient temperature. The means were divided by applying LSD test at $5 \%$ probability level and standard deviation was applied to the data (Table 5).

\begin{tabular}{|l|l|l|l|l|l|l|l|}
\hline \multicolumn{6}{|l}{ Storage intervals (hours) } \\
\hline $\begin{array}{l}\text { Treatmen } \\
\text { ts }\end{array}$ & $\begin{array}{l}\mathbf{0} \\
\text { Hours }\end{array}$ & $\begin{array}{l}\mathbf{2 4} \\
\text { Hours }\end{array}$ & $\begin{array}{l}\mathbf{4 8} \\
\text { Hours }\end{array}$ & $\begin{array}{l}\mathbf{7 2} \\
\text { Hours }\end{array}$ & $\begin{array}{l}\mathbf{9 6} \\
\text { Hours }\end{array}$ & $\begin{array}{l}\text { \% } \\
\text { Increase }\end{array}$ & $\begin{array}{l}\text { Mean } \\
\text { s }\end{array}$ \\
\hline $\mathrm{BG}_{0}$ & 0.92 & 0.92 & 0.92 & 0.91 & 0.91 & 1.098 & $0.91 \mathrm{a}$ \\
\hline $\mathrm{BG}_{1}$ & 0.9 & 0.9 & 0.89 & 0.88 & 0.88 & 2.22 & $0.89 \mathrm{~b}$ \\
\hline $\mathrm{BG}_{2}$ & 0.9 & 0.9 & 0.89 & 0.88 & 0.87 & 3.33 & $0.88 \mathrm{~b}$ \\
\hline $\mathrm{BG}_{3}$ & 0.89 & 0.89 & 0.88 & 0.87 & 0.86 & 3.37 & $0.87 \mathrm{c}$ \\
\hline $\mathrm{BG}_{4}$ & 0.87 & 0.86 & 0.86 & 0.85 & 0.84 & 3.45 & $0.85 \mathrm{e}$ \\
\hline $\mathrm{BG}_{5}$ & 0.89 & 0.89 & 0.88 & 0.87 & 0.87 & 2.25 & $0.88 \mathrm{c}$ \\
\hline $\mathrm{BG}_{6}$ & 0.88 & 0.88 & 0.87 & 0.86 & 0.85 & 3.37 & $0.86 \mathrm{~d}$ \\
\hline $\mathrm{Means}$ & $0.89 \mathrm{a}$ & $0.89 \mathrm{a}$ & $0.88 \mathrm{~b}$ & $0.87 \mathrm{c}$ & $0.86 \mathrm{~d}$ & & \\
\hline
\end{tabular}

Table 5: Effect of treatments and storage intervals on water activity of bread samples.

The samples $\mathrm{BG}_{3}, \mathrm{BG}_{4}, \mathrm{BG}_{5}$ and $\mathrm{BG}_{6}$ had lower water activity values as compared to the other samples, which might be due to the presence of turmeric powder in these samples. In a similar study, Lim et al. [20] found that increase levels of turmeric powder decrease the water activity of bread samples. He observed that the addition of $2 \%$ turmeric powder had $a_{W}$ of 9.5 while $5 \%$ addition of turmeric decreased to 9.4. This finding is closely related to observations of the present study.

\section{Overall acceptability}

Initially the mean score of judges for overall acceptability of samples were $7.8,7.1,6.9,7.7,7.5,7.4$ and 7.3 , which progressively decreased to $5.9,5.4,5.0,5.9,5.5,5.4$ and 5.3 correspondingly throughout storage. The overall mean score of judges for overall acceptability considerably 
$(\mathrm{P}<0.05)$ decreased from 7.38 to 5.48. For treatments, highest value for mean was noted in $\mathrm{BG}_{0}$ (6.96), followed by $\mathrm{BG}_{3}$ (6.88), while lowest value for mean was noted in $\mathrm{BG}_{1}$ and $\mathrm{BG}_{6}(6.36)$, followed by $\mathrm{BG}_{5}$ (6.46). Highest percent reduce was noted in $\mathrm{BG}_{2}$ (27.54\%), followed by BG6 (27.40\%), while lowest percent decrease was noted in $\mathrm{BG}_{3}$ (23.37\%), followed by BG 1 (23.94\%) (Table 6).

The statistical analysis showed that the treatments and storage intervals had a considerable $(\mathrm{P}<0.05)$ effect on the overall acceptability of bread samples throughout storage at ambient temperature. The means were divided by applying LSD test at $5 \%$ probability level and standard deviation was applied to the data (Table 6).

\begin{tabular}{|l|l|l|l|l|l|l|l|}
\hline \multicolumn{6}{|l}{ Storage intervals (hours) } \\
\hline $\begin{array}{l}\text { Treatmen } \\
\text { ts }\end{array}$ & $\begin{array}{l}\mathbf{0} \\
\text { Hours }\end{array}$ & $\begin{array}{l}\mathbf{2 4} \\
\text { Hours }\end{array}$ & $\begin{array}{l}\mathbf{4 8} \\
\text { Hours }\end{array}$ & $\begin{array}{l}\mathbf{7 2} \\
\text { Hours }\end{array}$ & $\begin{array}{l}\mathbf{9 6} \\
\text { Hours }\end{array}$ & $\begin{array}{l}\text { \% } \\
\text { Increase }\end{array}$ & $\begin{array}{l}\text { Mean } \\
\text { s }\end{array}$ \\
\hline $\mathrm{BG}_{0}$ & 7.8 & 7.5 & 7.1 & 6.5 & 5.9 & 24.36 & $6.96 \mathrm{a}$ \\
\hline $\mathrm{BG}_{1}$ & 7.1 & 6.9 & 6.5 & 5.9 & 5.4 & 23.94 & $6.36 \mathrm{~d}$ \\
\hline $\mathrm{BG}_{2}$ & 6.9 & 6.5 & 6.2 & 5.6 & 5 & 27.54 & $6.04 \mathrm{e}$ \\
\hline $\mathrm{BG}_{3}$ & 7.7 & 7.4 & 7 & 6.4 & 5.9 & 23.37 & $6.88 \mathrm{a}$ \\
\hline $\mathrm{BG}_{4}$ & 7.5 & 7.1 & 6.7 & 6.2 & 5.5 & 26.67 & $6.60 \mathrm{~b}$ \\
\hline $\mathrm{BG}_{5}$ & 7.4 & 7.1 & 6.6 & 5.8 & 5.4 & 27.02 & $6.46 \mathrm{c}$ \\
\hline $\mathrm{BG}_{6}$ & 7.3 & 6.9 & 6.4 & 5.9 & 5.3 & 27.4 & $6.36 \mathrm{~d}$ \\
\hline $\mathrm{Means}$ & $7.38 \mathrm{a}$ & $7.05 \mathrm{~b}$ & $6.64 \mathrm{c}$ & $6.04 \mathrm{~d}$ & $5.48 \mathrm{e}$ & & \\
\hline
\end{tabular}

Table 6: Effect of treatments and storage intervals on overall acceptability of bread samples.

\section{Conclusion}

From this study, it is concluded that ginger and turmeric does have inhibitory effect on the Rhizopus stolonifer growth of bread and these items can be used as natural spices for the improvement of shelf life of bread. The best inhibitory effect against Rhizopus stolonifer growth was observed in $\mathrm{BG}_{3}$, i.e. addition of $3 \%$ turmeric to bread flour. This treatment has shown positive effects on all other characteristics of bread including physicochemical and sensory attributes and is considered as the best treatment of this study. $\mathrm{BG}_{6}$, i.e. combination of both ginger and turmeric $2 \%$ each, also showed good results in inhibiting the growth of Rhizopus stolonifer but this treatment has affected other physicochemical and sensory characteristics. This study showed that ginger has a detrimental effect on the flavor of bread, while turmeric has no noticeable effect on the flavor or texture of bread.

\section{References}

1. Okoko FJ, Ogbomo O (2010) Amylolytic properties of fungi associated with spoilage in bread. Continental J Micro. 4: 1-7.oleoresins of Zingiber officinale. Food and Chemical Toxi 46: 3295-3302.

2. Liaqat $P$ (1988) Food Micro. National Book Foundation, Islamabad.

3. Skandamis PK, Koutsoumanis K, Fasseas, Nychas GJE (2001) Inhibition of oregano essential oil and EDTA on E. coli o157:H7. Italian J Food Sci 13: 55-65.

4. Benkeblia N (2004) Antimicrobial activity of essential oil extracts of various onions (Allium cepa) and garlic (Allium sativum). LWT Food Sci Tech 37: 263-268.
5. Burt S (2004) Essential oils their antibacterial properties and potential applications in foods a review. Int J Food Micro 94: 223-253.

6. Chutia MP, Dekabhuyan MG, Pathak TC, Sarma, Boruah P (2009) Antifungal activity and chemical composition of citrus (reticulata blanco) essential oil against phytopathogens from North East India. LWT Food Sci Tech 42: 777-780.

7. Hathorn CS, Biswas MA, Gichuhi PN, Benjamin ACB (2008) Comparison of chemical, physical, micro structural and microbial properties of breads supplemented with sweet potato flour and highgluten dough enhancers. LWT - Food Sci Tech 41: 803-815.

8. Peirce A (1999) The American Pharmaceutical Association. Practical guide to natural medicines.. The Stone Song Press, New york.

9. Eigner D, Scholz D (1999) Ferula asafoetida and Curcuma longa in traditional medical treatment and diet in Nepal. J Ethnopharmacology 67: 1-6.

10. Ruby JG, Kuttan KD, Babu KN, Rajashekharan, Kuttan R (1995) Antitumor and oxidant activity of natural curcumnoids. Cancer Lett 94: 79-83.

11. Lean LP, Mohamed S (1999) Antioxidative and antimycotic effects of turmeric, lemon grass, betel leaves, clove, black pepper leaves and Garcinia atriviridis on butter cakes. J Sci Food Agri 79: 1817-1822.

12. Prathapan A, Lukhman M, Arumughan C, Sundaresan A, Raghu KG (2009) Effect of heat treatment on curcuminoid, colour value and total polyphenols of fresh turmeric rhizome. Int J Food Sci Tech 44: 1438-1444.

13. Jayaprakasha GK, Jaganmohan R, Sakariah KK (2006) Antioxidant activities of curcumin, demethoxycurcumin and bisdemethoxycurcumin. Food Chem 98: 720-724.

14. Singh GIPS, Kapoor P, Singh S, Heluani C, Lampasona DP (2008) Chemistry antioxidant and antimicrobial investigations on essential oil and oleoresins of Zingiber officinale. Food Chem Toxi 46: 3295-3302.

15. Ali BHG Blunden, Tanira MO, Nemmar A (2008) Some phytochemical, antioxidant and tyrosinase inhibition properties of leaves and rhizomes of ginger species. Food Chemistry 109: 477-483.

16. Stoilova IA, Krastanov A, Stoyanova P, Denev, Gargova S (2007) Antioxidant activity of a ginger extract (Zingiber officinale). Food Chem 102: 409-420.

17. Kikuzaki H, Nakatani N (1993) Antioxidant effects of some ginger constituents. J Food Sci 58: 1407-1410.

18. Kim JK, Kim Y, Surh YJ, Kim TY (2007) Gingerol prevents UVB induced ROS production and COX-2 expression in vitro and in vivo. Free Radical Res 41: 603-614.

19. Vasala PA (2001) Ginger. Handbook of herbs and spice.

20. Lim HS, Park SH, Ghafoor K, Hwang SY, Park J (2011) Quality and antioxidant properties of bread containing turmeric (Curcuma longa L.) cultivated in South Korea. Food Chem 124: 1577-1582.

21. AACC (2000) Approved Methods of the American Association of Cereal Chemists. The American Association of Cereal Chemists. Inc St Paul, Minnesota, USA.

22. Beneke ES (1962) Medical Mycology Lab Manual. Burgess Pub. Co Minneapolis Minnesota. Boca Raton Washington, Peter CRC Press, DC.

23. AOAC (2012) Official methods of analysis. Association of official Analytical Chemists. (19th Edition), Gaithersburg, MD, USA.

24. Larmond E (1997) Methods for sensory evaluation of food. Food Research Institute, Central Experimental farm, Ottawa, Canada, Publication.

25. Steel R, Torie J (1980) Mathematical Statistics (2nd Edition).

26. Rehman SUS, Hussain H, Nawaz MM, Ahmad MA, Murtaza, et al. (2007) Inhibitory effect of citrus peel essential oils on the microbial growth of bread. Asian Network for Scientific Information. Pak J Nut 6: 558-561.

27. Hocking AD (1988) Molds and yeasts associated with foods of reduced water activity. Ecological interactions in food preservation by moisture control. Elsevier. London and NY 34: 56-57. 
Citation: Muhammad A, Rahman Z, Ayub M, Durrani Y, Ali SA, et al. (2014) Inhibitory Effect of Ginger and Turmeric on Rhizopus stolonifer Growth on Bread . J Food Process Technol 5: 325. doi:10.4172/2157-7110.1000325

Page 6 of 6

28. Fik M, Surowka K, Maciejaszek I, Macura M, Michalczyk M (2012) Quality and shelflife of calcium enriched whole meal bread stored in a modified atmosphere. J Cereal Sci 56: 418-424.

29. Kang SK (2007) Changes in organic acid, mineral, color, curcumin and bitter substance of curcuma longa L. and Curcuma atomatica Salib. according to picking time. Korean J Food Pres 14: 633-638.
30. Bojnanska TF, Helena L, Miriam, Marian T (2012) Legumes, the alternative raw materials for bread production. J Micro Biotech Food Sci1: 876-886.

31. Shin DJ, Kim W, Kim Y (2013) Physicochemical and sensory properties of soy bread made with germinated, steamed, and roasted soy flour. Food Chem 141: 517-523. 